\title{
Alterations in Functional Cortical Hierarchy in Hemiparkinsonian Rats
}

\author{
Borbála Nóra Jávor-Duray, ${ }^{1}$ Martin Vinck, ${ }^{2}$ Marcel van der Roest, ${ }^{1}{ }^{\circledR E r w a n ~ B e z a r d, ~}{ }^{3,4}$ Henk W. Berendse, ${ }^{5}$ \\ (T)Thomas Boraud, ${ }^{3,4}$ and Pieter Voorn ${ }^{1}$ \\ ${ }^{1}$ Department of Anatomy and Neurosciences, VU University Medical Center, Amsterdam Neuroscience, 1081 BT Amsterdam, The Netherlands, ${ }^{2}$ Ernst \\ Strüngmann Institut for Neuroscience in Cooperation with Max Planck Society, 60528 Frankfurt am Main, Germany, ${ }^{3}$ Université de Bordeaux, Institut des \\ Maladies Neurodégénératives, Unité Mixte de Recherche 5293, F-33000 Bordeaux, France, ${ }^{4}$ Centre National de la Recherche Scientifique, Institut des \\ Maladies Neurodégénératives, Unité Mixte de Recherche 5293, F-33000 Bordeaux, France, and ${ }^{5}$ Department of Neurology, VU University Medical Center, \\ Amsterdam Neuroscience, 1081 HV Amsterdam, The Netherlands
}

Parkinson's disease and experimentally induced hemiparkinsonism are characterized by increased beta synchronization between cortical and subcortical areas. This change in beta connectivity might reflect either a symmetric increase in interareal influences or asymmetric changes in directed influences among brain areas. We assessed patterns of functional and directed connectivity within and between striatum and six cortical sites in each hemisphere of the hemiparkinsonian rat model. LFPs were recorded in resting and walking states, before and after unilateral 6-hydroxydopamine lesion. The hemiparkinsonian state was characterized by increased oscillatory activity in the $20-40 \mathrm{~Hz}$ range in resting and walking states, and increased interhemispheric coupling (phase lag index) that was more widespread at rest than during walking. Spectral Granger-causality analysis revealed that the change in symmetric functional connectivity comprised profound reorganization of hierarchical organization and directed influence patterns. First, in the lesioned hemisphere, the more anterior, nonprimary motor areas located at the top of the cortical hierarchy (i.e., receiving many directed influences) tended to increase their directed influence onto the posterior primary motor and somatosensory areas. This enhanced influence of "higher" areas may be related to the loss of motor control due to the 6-OHDA lesion. Second, the drive from the nonlesioned toward the lesioned hemisphere (in particular to striatum) increased, most prominently during walking. The nature of these adaptations (disturbed signaling or compensation) is discussed. The present study demonstrates that hemiparkinsonism is associated with a profound reorganization of the hierarchical organization of directed influence patterns among brain areas, perhaps reflecting compensatory processes.

Key words: 6-OHDA lesion; functional connectivity; Granger causality; LFPs; Parkinson's disease; striatum

Significance Statement

Parkinson's disease classically first becomes manifest in one hemibody before affecting both sides, suggesting that degeneration is asymmetrical. Our results suggest that asymmetrical degeneration of the dopaminergic system induces an increased drive from the nonlesioned toward the lesioned hemisphere and a profound reorganization of functional cortical hierarchical organization, leading to a stronger directed influence of hierarchically higher placed cortical areas over primary motor and somatosensory cortices. These changes may represent a compensatory mechanism for loss of motor control as a consequence of dopamine depletion.

\section{Introduction}

Abnormal synchronization of neuronal oscillatory activity in the beta frequency range within and between cortex and basal ganglia

Received Oct. 21, 2016; revised March 7, 2017; accepted March 12, 2017.

Author contributions: B.N.J.-D., M.V., M.v.d.R., H.W.B., and P.V. designed research; B.N.J.-D., M.v.d.R., and P.V. performed research;B.N.J.-D., M.V., T.B., and P.V. analyzed data;B.N.J.-D., M.V., M.v.d.R., E.B., H.W.B., T.B., and P.V. wrote the paper.

This work was supported by European Commission, European Erasmus Mundus Programme to B.J.-D. This publication reflects the views only of the author, and the Commission cannot be held responsible for any use that may be made of the information contained therein. has been established as an important pathophysiological mechanism in Parkinson's disease (for review, see Stein and Bar-Gad, 2013). However, neither the pathophysiological and functional relevance nor the origin of these changes is as yet clear. Animal experimental evidence has shown that loss of nigral dopaminer-

The authors declare no competing financial interests.

Correspondence should be addressed to Dr. Pieter Voorn, VU University Medical Center, Department of Anatomy and Neurosciences, De Boelelaan 1108, 1081 HZ Amsterdam, The Netherlands. E-mail: p.voorn@vumc.nl. DOI:10.1523/JNEUROSCI.3257-16.2017

Copyright $\odot 2017$ the authors $\quad 0270-6474 / 17 / 377669-13 \$ 15.00 / 0$ 
gic neurons results in excessive beta band oscillatory activity and increased coupling (Degos et al., 2009; Brazhnik et al., 2012; Dejean et al., 2012; Jávor-Duray et al., 2015). Studies in patients suggest that dopamine depletion might also induce compensatory mechanisms that counteract disturbances in motor control (Silberstein et al., 2005; Stoffers et al., 2008; Beeler et al., 2013; Pollok et al., 2013). In a previous paper, we found support for such mechanisms by showing in the hemiparkinsonian rat model enhanced interhemispheric coupling between primary motor cortices and directional information flow from the nonlesioned toward the lesioned hemisphere (Jávor-Duray et al., 2015).

Compensatory processes likely involve other components of cortex-basal ganglia networks in addition to primary motor cortex (Sabatini et al., 2000; Lalo et al., 2008; Palmer et al., 2009; Helmich et al., 2010; Michely et al., 2015; Oswal et al., 2016). Structural connectivity studies have elucidated an elaborate network of interconnected cortical regions and basal ganglia sectors involved in motor control. These regions not only encompass motor and premotor areas but also somatosensory and prefrontal cortices (Mao et al., 2011; Bedwell et al., 2014; Groenewegen et al., 2016). Interestingly, on the basis of structural connectivity data, a cortical circuit model has recently been proposed in which information flow is directed from somatomotor and sensory areas to association areas in prefrontal and temporal cortex, defining a hierarchical organization (Chaudhuri et al., 2015). Modeling based on structural connectivity among visual, parietal, and frontal areas has been shown to correlate very well with functional modeling (Markov et al., 2014; Bastos et al., 2015; Michalareas et al., 2016). Together, these findings suggest that directional connectivity and hierarchical functional organization might play an important role in changes affecting networks encompassing frontal association and motor regions that occur as a consequence of loss of dopamine. Because functional (synaptic) as well as morphological plasticity is regulated by dopamine (Lovinger, 2010; Villalba and Smith, 2013), dysfunctional dopaminergic neurotransmission may lead to both functional and structural neural circuit changes in striatum as well as in cortex (Friston et al., 2012; Beeler et al., 2013).

Recent studies show that changes in directional connectivity may occur in neurological disorders (Dauwan et al., 2016; Žarić et al., 2017). Such changes have not yet been reported in (experimental models of) Parkinson's disease. Therefore, in the present study, we sought to establish the functional relationships of the rat primary motor cortex and pathological changes thereof incurred by unilateral depletion of dopamine. To this end, we used the hemiparkinsonian rat model because its neurophysiological characteristics closely resemble those observed in Parkinson's disease patients, including changes in the pattern of oscillatory activity, disturbances in connectivity patterns, and response to therapy (Brazhnik et al., 2012; Q. Li et al., 2012; Jávor-Duray et al., 2015). Moreover, the model allows studying interhemispheric responses to asymmetric nigral degeneration, which is found in most early-stage Parkinson's disease patients (Scherfler et al., 2012; Mostile et al., 2015). Functional and effective connectivity patterns were defined by recording LFPs from 14 cortical and striatal brain areas across the two hemispheres in freely behaving normal and hemiparkinsonian rats, at rest and during locomotor activity. Hemispheric asymmetries were examined at three levels: power, connectivity, and Granger causal (GC) influences. For determining the hierarchical position of an area in the network, the pattern of directed influences was established by using GC influence data to calculate the "directed asymmetry index," a measure that has been successfully used in correlating functional to structural hierarchical modeling among visual, parietal, and frontal areas (Markov et al., 2014; Bastos et al., 2015; Michalareas et al., 2016).

\section{Materials and Methods}

Animals. Male Wistar rats ( $2300 \mathrm{~g}$, Harlan) were kept under standard housing conditions at a constant temperature $\left(22 \pm 1^{\circ} \mathrm{C}\right)$, humidity (relative, 56\%), and $12 \mathrm{~h}$ reverse light-dark cycle (daylight period 19:007:00). Food and water were available ad libitum throughout the experiment. All behavioral sessions were conducted during the dark phase, at the same time of the day. The study was approved by the Animal Ethical Committee at the VU University of Amsterdam, and it was conducted in accordance with Dutch (Wet op de Dierproeven, 1996) and European regulations (Guideline 86/609/EEC).

Recording device and surgery. A custom-made recording device was designed to allow simultaneous multielectrode recordings from in total 14 cortical and striatal brain areas (see Fig. 1A). The design allowed long-term LFP recordings from the same location throughout the course of the experiment; all areas were recorded bilaterally: that is, both in the lesioned (left) and the nonlesioned (right) hemisphere. Subcortical electrodes were implanted in dorsolateral striatum (1.0/3.0/3.9, target coordinates given relative to bregma, dorsoventral relative to dural surface in millimeters: anteroposterior/mediolateral/dorsoventral based on Paxinos and Watson, 2005). The cortical recording sites spanned both caudally located primary and somatosensory areas: the caudal forelimb area in the primary motor cortex, motor forelimb area (M1FL) 1.0/2.2/2; the caudal hindlimb area in the primary motor cortex, motor hindlimb area (M1HL) $-1.8 / 1.6 / 2$; and the primary somatosensory areas for hind limbs, S1HL $-1.8 / 3.0 / 2$; but also more rostrally and medially positioned frontal areas. These included the mPFC (3.2/0.7/3.5), secondary motor areas (M2: 2.0/1.5/2), which is also referred to as the vibrissal-frontal eye system (Gioanni and Lamarche, 1985; Neafsey et al., 1986), and the rostral motor area (RMA: 4.0/2.5/2) that has been considered a nonprimary motor area (Donoghue and Wise, 1982). The recording device was constructed from a custom-made electrode holder (3D printed, $11 \mathrm{~mm}$ diameter, $11 \mathrm{~mm}$ height) allowing precise positioning of the 14 stainlesssteel wires (50 $\mu \mathrm{m}$ diameter), according to the coordinates of the targeted brain areas.

Inhalation anesthesia with isoflurane was used to initiate and maintain anesthesia throughout the implantation procedure: mixed isoflurane $2.5 \%-1.75 \%$ in $\mathrm{O}_{2}(0.3 \mathrm{~L} / \mathrm{min}) / \mathrm{N}_{2} \mathrm{O}(0.6 \mathrm{~L} / \mathrm{min})$. Placement holes for electrodes and the cannula (used for neurotoxin injection later in the experiments) were marked and drilled in the skull, which was fixed in the stereotactic frame (Kopf). All electrodes were placed in the corresponding locations (in the range of anteroposterior -1.8 to 4.0 , mediolateral 0.7 to 3.0; dorsoventral for cortical electrodes $2 \mathrm{~mm}$; for $\mathrm{mPFC}$, striatum 3.5, $3.9 \mathrm{~mm}$ below dura; see Fig. $1 \mathrm{~A}$ ). The electrode holder device was fixed to the skull with dental cement and anchor screws. A common reference/ground wire for all electrodes was attached to a stainless-steel screw placed above the left cerebellar hemisphere. Next, the guide cannula for the subsequent 6-OHDA injections was placed above the medial forebrain bundle (at $18^{\circ}$ anteroposterior angle, anteroposterior -7 , mediolateral 1.9, dorsoventral $7 \mathrm{~mm}$ from dural surface). After surgery, the animals were allowed to recover for $7 \mathrm{~d}$.

6-OHDA lesion procedure. For the duration of the 6-OHDA injection, animals were anesthetized with isoflurane $(2.5 \%)$. The injection needle was inserted in the guide cannula (extending $1 \mathrm{~mm}$ from end of cannula); $8 \mu \mathrm{g} 6$-OHDA (Sigma) in $3 \mu \mathrm{l} 0.9 \%$ saline $\mathrm{NaCl}$ stabilized with $0.05 \%$ ascorbic acid was injected with a Hamilton needle (rate: $0.250 \mu \mathrm{l} / \mathrm{min}$ ). After completing the injection, the injector was left in place for 3 additional minutes to prevent the solution from flowing back up the guide.

Multielectrode recordings in behaving animals. The animals were recorded in the active period of the day in two behavioral conditions: rest (quiescence) and walk (locomotion). To record rest-related signals, the rats were placed in a home-like cage and were allowed to explore the environment freely. To acquire movement-related signals, the animals were trained (in 3-6 sessions) to execute a simple task to walk in an elongated behavioral box, encouraged by sucrose pellets at both ends of the 1-m-long corridor (for details, see Jávor-Duray et al., 2015). After the postoperative recovery period, we performed serial recordings of freely 
moving and behaving animals before and $>14 \mathrm{~d}$ after the 6-OHDA injection, when effects of the neurotoxin are expected to be complete. For resting (sitting) measurements, animals were placed in a home cage $(50 \times 30 \mathrm{~cm}$ Plexi Faraday cage), recorded for $20 \mathrm{~min}$, followed by a behavioral task session (maximum $20 \mathrm{~min}$, depending on their performance). The electrode position was fixed over the course of experiments enabling comparison of the same neuronal population over time. The acquired LFPs, sampled at $1 \mathrm{kHz}$, were amplified 20× (HST/16V-G20), followed by a preamplifier (PBX/32sp-r G50/16fp-G50, Plexon) with 50 $\times$ gain. The signal was bandpass filtered to generate LFPs $(0.7-170 \mathrm{~Hz})$. Video recordings (Cineplex, Plexon) and behavioral data (MEDPC), both synchronized with the LFPs, were stored for offline analysis.

Resting and movement intervals were selected using Cineplex Markup software (Plexon). Two major behavioral patterns were distinguished: rest (closest possible to the human resting state); awake, sitting animal, without any major motor activity (washing-grooming, etc.) involving $>1 \mathrm{limb} /$ shoulder girdle (considered as an alert state); and walk, animal standing on 4 limbs, performing step by step motion (only clear locomotion-associated signal was included in the analysis). We compared behavioral parameters of presessions and postsessions with Welch's $t$ test (two-tailed, $p<0.05$ ), presented as mean \pm SD. For the analysis of electrophysiological data, if a single recording session provided $<60$ s of walking behavior, we pooled recordings from consecutive days.

Histology. Electrode placements were validated by postmortem histological analysis of the brains. After the final recording, the rats were anesthetized with isoflurane, the recording sites were marked by passing a direct current through every electrode. Then the animals were injected with medetomidine $(0.25 \mathrm{ml} / \mathrm{kg}$, i.p.), ketamine ( $10 \% 0.7 \mathrm{ml} / \mathrm{kg}$, i.p. $)$, and perfused intracardially with buffered $4 \%$ PFA. After perfusion, the brains were removed and immersion-fixed in the same fixative. Coronal brain sections $(40 \mu \mathrm{m})$ were cut from substantia nigra (anteroposterior: -6.6 to $-4.5 \mathrm{~mm}$ ) for electrode placement validation (anteroposterior: -3.5 to $-4.0 \mathrm{~mm}$ ). Slides from all structures were stained with cresyl violet for tracing the electrode tracts. Slides from substantia nigra were immunostained for tyrosine hydroxylase $(\mathrm{TH})$ for quantitative assessment of dopaminergic cell loss (see Fig. 1B). Briefly, free-floating brain tissue sections were incubated with mouse-anti rat TH (Incstar) diluted 1:2000 in TRIS-buffered saline. Washings between incubation steps were in the same buffer. After incubating with biotinylated-horse-anti-mouse IgG (Vector Laboratories; 1:100), peroxidase was visualized using an ABC immunoperoxidase kit (Vector Laboratories; $1: 200$ ) and DABtetrahydrochloridedihydrate (Sigma; $0.5 \mathrm{mg} / \mathrm{ml}$ ) as chromogen.

The extent of the 6-OHDA lesions was quantified independently by two observers using an ordinal 5-point scale to assess microscopically the number of dopaminergic cell bodies that was present in ventral tegmental area and substantia nigra at the end of the experiment. The lesioned side was compared with the nonlesioned side. In no case had the neurotoxin injection affected the noninjected side. The scale used was as follows: 1 , no effect of lesion; $2,>50 \%$ of the dopaminergic cell bodies are present; $3,<50 \%$ but $>10$ cells are present; $4,<10$ cells are present; 5 , not a single cell present. Six or seven coronal sections through the mesencephalon, covering a range of bregma anteroposterior -6.20 to -4.30 , were rated per animal, and ratings were averaged to obtain a final score. Interrater consistency was calculated using Cohen's $\kappa$ agreement between the evaluations of the two raters. Quantification of cell loss showed an average score of 3 in ventral tegmental area in 3 of 5 cases, meaning that $<50 \%$ of the dopaminergic cell bodies were still present. In 2 cases, more cell bodies were preserved (average scale 1.2, 1.3) in the ventral tegmental area. In all cases, substantia nigra was virtually depleted of TH-immunopositive neurons (see Fig. 1B). Agreement between the two independent observers, as calculated using Cohen's $\kappa$ measure, was 0.467 for substantia nigra $(p=0.020)$ and 0.7 for ventral tegmental area $(p=0.001)$.

Data analysis. All data were analyzed using custom-made MATLAB scripts (B.N.J.-D., M.V.) and the Fieldtrip toolbox (Oostenveld et al., 2011). The analysis of power and coherence spectra was performed as in Jávor-Duray et al. (2015). For a given behavioral period (e.g., quiescence), we divided all available LFP recordings into segments of $2 \mathrm{~s}$ (see
Fig. $1 C$ ). The $50 \mathrm{~Hz}$ line noise artifact was removed from the data by fitting a $50 \mathrm{~Hz}$ sinusoid to the data and subtracting this (Fries et al., 2008). For every segment, we then estimated the power spectral density and cross-spectral density by using the Discrete Fourier Transform in combination with multitapering, using a spectral resolution of $2 \mathrm{~Hz}$ in case of the sitting period, and $6 \mathrm{~Hz}$ in case of the walking period (we used a coarser frequency resolution, as fewer observations were available). The relative power spectra were computed by dividing the power with the total power. The phase lag index (PLI) (Stam et al., 2007) was computed as follows. The direct PLI estimator is defined as follows:

$$
\hat{\psi}^{s} \equiv \frac{1}{N} \sum_{j=1}^{N} \operatorname{sgn}\left(\mathfrak{I}\left\{X_{j}\right\}\right),
$$

Instead, we computed the unbiased estimator of the PLI (Vinck et al., 2011) as follows:

$$
\hat{\Omega} \equiv\left(\begin{array}{l}
N \\
2
\end{array}\right)^{-1} \sum_{j=1}^{N-1} \sum_{k=(j+1)}^{N} d\left(X_{j}, X_{k}\right)
$$

where

$$
d(U, V) \equiv \operatorname{sgn}(\mathfrak{I}\{\mathrm{U}\}) \operatorname{sgn}(\mathfrak{I}\{\mathrm{V}\})
$$

The PLI computes the nonequiprobability of phase leads and lags, with a value of 0 indicating that there are no systematic phase leads and lags and a value of 1 indicating that one channel is always phase leading or lagging the other channel.

GC flow was computed using nonparametric spectral density estimation (using spectral matrix factorization) according to Dhamala et al. (2008). It has been shown that additive noise (e.g., because of a common reference, or volume conduction) can distort GC measures, leading to erroneous conclusions about who is the causal driver and recipient (Vinck et al., 2015). As a control, we therefore computed GC measures on time-reversed signals (Haufe et al., 2013; Vinck et al., 2015), which has been shown to be a conservative control for signal-to-noise ratio differences and common noise (Vinck et al., 2015). To establish that GC flow from area $\mathrm{A}$ to $\mathrm{B}$ is stronger than $\mathrm{GC}$ flow from area $\mathrm{B}$ to $\mathrm{A}$, we required not only a significant GC asymmetry for the actual data $(\mathrm{A} \rightarrow \mathrm{B}>\mathrm{B} \rightarrow$ A), but also a significant GC asymmetry for time-reversed signals in the opposite direction $(\mathrm{B} \rightarrow \mathrm{A}>\mathrm{B} \rightarrow \mathrm{A})$.

Results of relative power, PLI, and GC analyses were compared between presessions and postsessions with a two-sampled $t$ test (two tailed, $p<0.05)$.

To assess the spatial distribution of dopamine cell loss-induced changes in functional connectivity and directionality, we estimated the average PLI and GC changes over the beta frequencies and computed significant changes with a two-sampled $t$ test (two tailed, $p<0.05$ ).

Hierarchical ordering within the lesioned hemisphere. The extent to which an area tended to be a "driver" or a "receiver" within the lesioned hemisphere was quantified as follows:

1. For each $m$ out of $M$ areas within the lesioned hemisphere, we computed the GC influence from that area toward each other area, and from all the other areas toward that area. This yielded GC-in ${ }_{\mathrm{m}, \mathrm{k}}$ and GC-out $\mathrm{m}_{\mathrm{k}, \mathrm{k}}$ values for area $m$ and $k$ (i.e., GC inflow and GC outflow values).

2. For each area combination, we then computed the directional

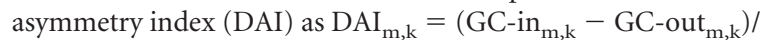
$\left(\mathrm{GC}_{\mathrm{in}, \mathrm{k}}+\mathrm{GC}_{\mathrm{out}} \mathrm{m}, \mathrm{k}\right.$ ), as in Bastos et al. (2015) and Michalareas et al. (2016).

3. We then averaged these DAI values across the $M$ areas (excluding the $m$-th area itself), yielding an average $\mathrm{DAI}_{\mathrm{m}}$ value for all $M$ areas.

The $\mathrm{DAI}_{\mathrm{m}}$ values range from -1 to 1 . A value of 1 indicates that an area tends to be a receiver (i.e., sits at a top of the cortical hierarchy) (Bastos et al., 2015; Michalareas et al., 2016). These values are shown in Figure 7A, $B$. As a measure of hierarchical ordering, we computed the variance 
$\operatorname{Var}\left\{\mathrm{DAI}_{\mathrm{m}}\right\}$ across the $M$ areas, which is shown in Figure 7C. We also computed, for each $m$-th area, the average $\mathrm{GC}-\mathrm{in}_{\mathrm{m}}$ and $\mathrm{GC}-$ out $_{\mathrm{m}}$ values by averaging the GC-in ${ }_{\mathrm{m}, \mathrm{k}}$ and GC-out ${ }_{\mathrm{m}, \mathrm{k}}$ values across the $M$ areas.

Hierarchical ordering between hemispheres. The extent to which an area within the nonlesioned hemisphere tended to be a "driver" or a "receiver" with respect to the lesioned hemisphere was quantified as follows:

1. For each $m$ out of $M$ areas within the nonlesioned hemisphere, we computed the GC influence from that area toward all other areas in the lesioned hemisphere, and from all the other areas in the lesioned hemisphere toward that area. This yielded $\mathrm{GC}-\mathrm{in}_{\mathrm{m}, \mathrm{k}}$ and GC-out $_{\mathrm{m}, \mathrm{k}}$ values for area $m$ (in nonlesioned hemisphere) and $k$ (in lesioned hemisphere).

2. For each area combination, we then computed the DAI as $\mathrm{DAI}_{\mathrm{m}, \mathrm{k}}=(\mathrm{GC}$ in $_{\mathrm{m}, \mathrm{k}}-$ GC-out $\left._{\mathrm{m}, \mathrm{k}}\right) /\left(\mathrm{GC}-\mathrm{in}_{\mathrm{m}, \mathrm{k}}+\right.$ GC-out ${ }_{\mathrm{m}, \mathrm{k}}$ ).

3. We then averaged these DAI values across the $M$ areas in the lesioned hemisphere, yielding an average $\mathrm{DAI}_{\mathrm{m}}$ value for all the $M$ areas in the nonlesioned hemisphere. These values are shown in Figure $8 B$.

To quantify the change in GC between areas induced by the 6-OHDA lesion, we computed the average GC flow from the nonlesioned to the lesioned hemisphere and from the lesioned to the nonlesioned hemisphere by averaging $\mathrm{GC}^{-\mathrm{in}_{\mathrm{m}, \mathrm{k}}}$ and GC-out $\mathrm{m}_{\mathrm{k}, \mathrm{k}}$ across all the leftright area combinations. This yielded, per session, an average GC value from left to right, and from right to left. We then examined whether these values differed between prelesion and postlesion and whether there was an interaction with behavioral state (see Fig. 8A).

\section{Results \\ 6-OHDA-induced subtle parkinsonism}

We induced dopamine cell loss by performing 6-OHDA injections in 5 rats and compared the behavioral and electrophysiological outcome measures between the prelesion period and the postlesion period. The start of the postlesion period was defined as $14 \mathrm{~d}$ after the 6-OHDA injection (see Materials and Methods).

We first examined whether the 6-OHDA lesion led to changes in spontaneous or task behavior. We found that walking speed decreased significantly after the lesion $(0.440 \pm 0.075 \mathrm{~m} / \mathrm{s}$ vs $0.335 \pm 0.134 \mathrm{~m} / \mathrm{s}$, prelesion vs postlesion, $p=0.009, t$ test, $t=$ 2.06). Performance in a pellet-chasing task (see Materials and Methods) decreased significantly for the number of collected pellets (prelesion: $33 \pm 9$; postlesion: $18 \pm 16$ pellets, $p<0.01, t=$ 2.01). The relative time spent in the monitored behaviors did not change for quiescence and showed less time in the postlesion condition (i.e., time spent locomoting relative to the length of the recording session; quiescence: $0.477 \pm 0.248$ vs $0.583 \pm 0.1966, p=$ $0.048, Z=1.72$, Mann-Whitney $U$ test; locomotion: $0.188 \pm 0.082$ vs $0.159 \pm 0.093, p=0.105, Z=1.24, \alpha=0.05$, Mann-Whitney $U$ test). Thus, we found moderately disturbed performance in the motor task after the 6-OHDA injection.

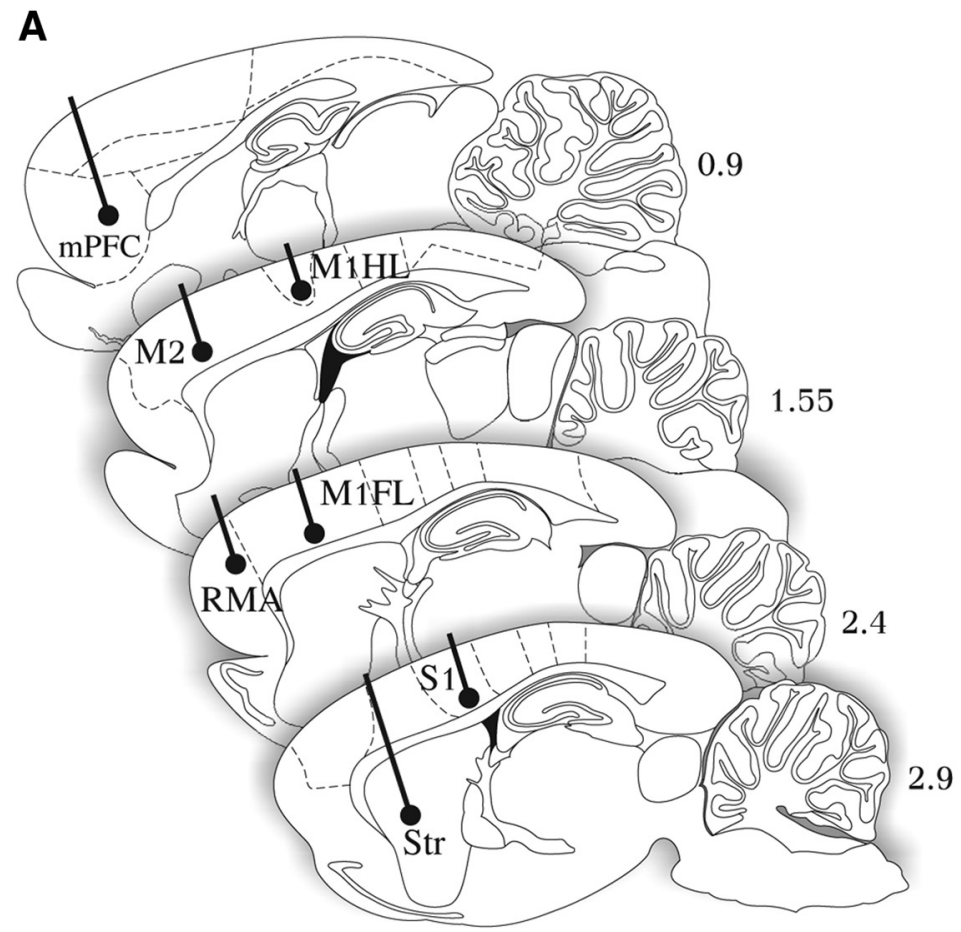

2.9

Figure 1. Electrode placements and 6-0HDA lesion. A, Localization of recording electrodes in sagittal rat brain sections at 4 lateral-to-medial levels indicated in millimeters relative to midline (for details, see Materials and Methods: Recording device and surgery). $\boldsymbol{B}$, Representative coronal section immunostained for TH at the level of substantia nigra. There is an absence of immunopositive neurons in substantia nigra in the 6-OHDA-injected side of the brain (right). SN, Substantia nigra; Str, striatum.

\section{6-OHDA-induced changes in oscillatory power}

We first examined changes in relative power spectra from all 14 brain areas. In total, we analyzed data from on average $3 / 3.4$ prelesion, and 4.8/3.4 (quiescence/locomotion) postlesion condition recording sessions per rat $(n=5)$, with $586 \pm 288 \mathrm{~s}$ and $97 \pm 24$ s of data per session for quiescence and locomotion, respectively.

Both during quiescence and locomotion, we observed significant increases in relative power for the high beta-low gamma frequencies in most recorded brain areas, particularly in the lesioned hemisphere, with a characteristic $\sim 30 \mathrm{~Hz}$ peak emerging in the power spectra after the lesion had developed (Figs. 1, 2). For the remainder of the manuscript, we will focus our analyses on the $20-40 \mathrm{~Hz}$ band that we refer to as the "beta" band. The increase in beta power tended to be least pronounced in the most caudal areas (M1HL and S1HL) but encompassed both primary and nonprimary frontal areas (Fig. 2). We also found that the beta power increase depended on the behavioral state. After the 6-OHDA lesion, average beta power in the nonlesioned (left) hemisphere increased during quiescence, but not during locomotion (Fig. $2 ; p=$ 0.03 for interaction lesion $\times$ behavior, $2 \times 2$ ANOVA; $p=0.31$ for main effect of lesion). Furthermore, compared with the prelesion baseline, we observed a nonsignificant trend for the increase in beta- 
Left hemisphere (non-lesioned)
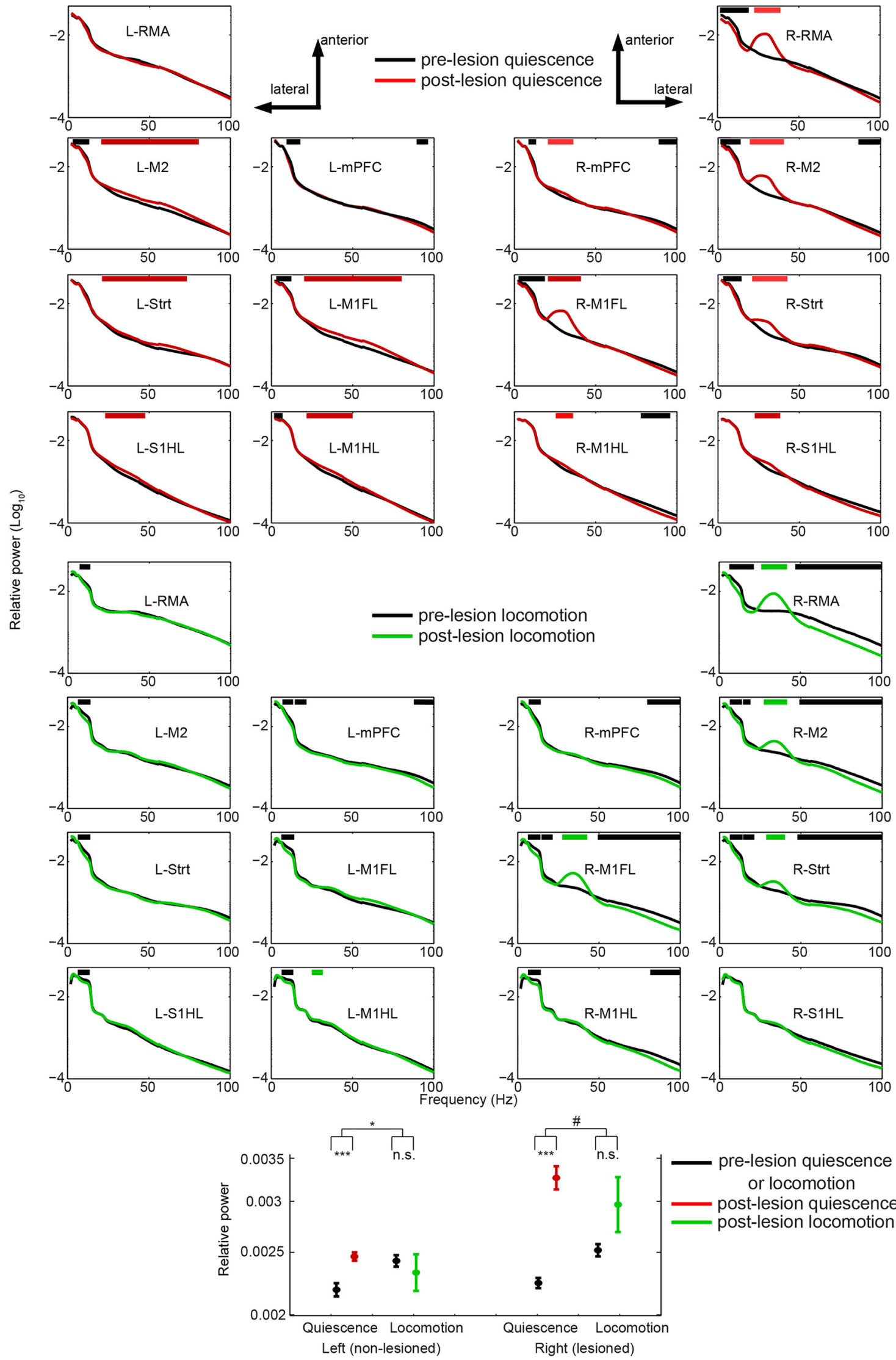

_ pre-lesion quiescence or locomotion

post-lesion quiescence post-lesion locomotion

$\Phi$

Quiescence Locomotion Right (lesioned)

Figure 2. Changes in LFP power after nigrostriatal dopamine degeneration. Average relative power (shading represents SEM over recording sessions) at baseline (pre, black) and lesioned (post: $>14 \mathrm{~d}$ after 6-OHDA injection) conditions for quiescence (red) and locomotion (green). Horizontal red and green bars indicate significant increments prelesion and postlesion respectively. Black bars indicate significant decrements $(p<0.05)$. $x$-axis, frequency $(\mathrm{Hz}) ; y$-axis, relative power $\left(\log _{10}\right.$ transformed). ${ }^{*} p<0.05$ two-way ANOVA, main effect of behavior, ${ }^{* * *} p<0.01$ Student's $t$-test, $\# 0.05<p<0.10$ two-way ANOVA, main effect of behavior. 


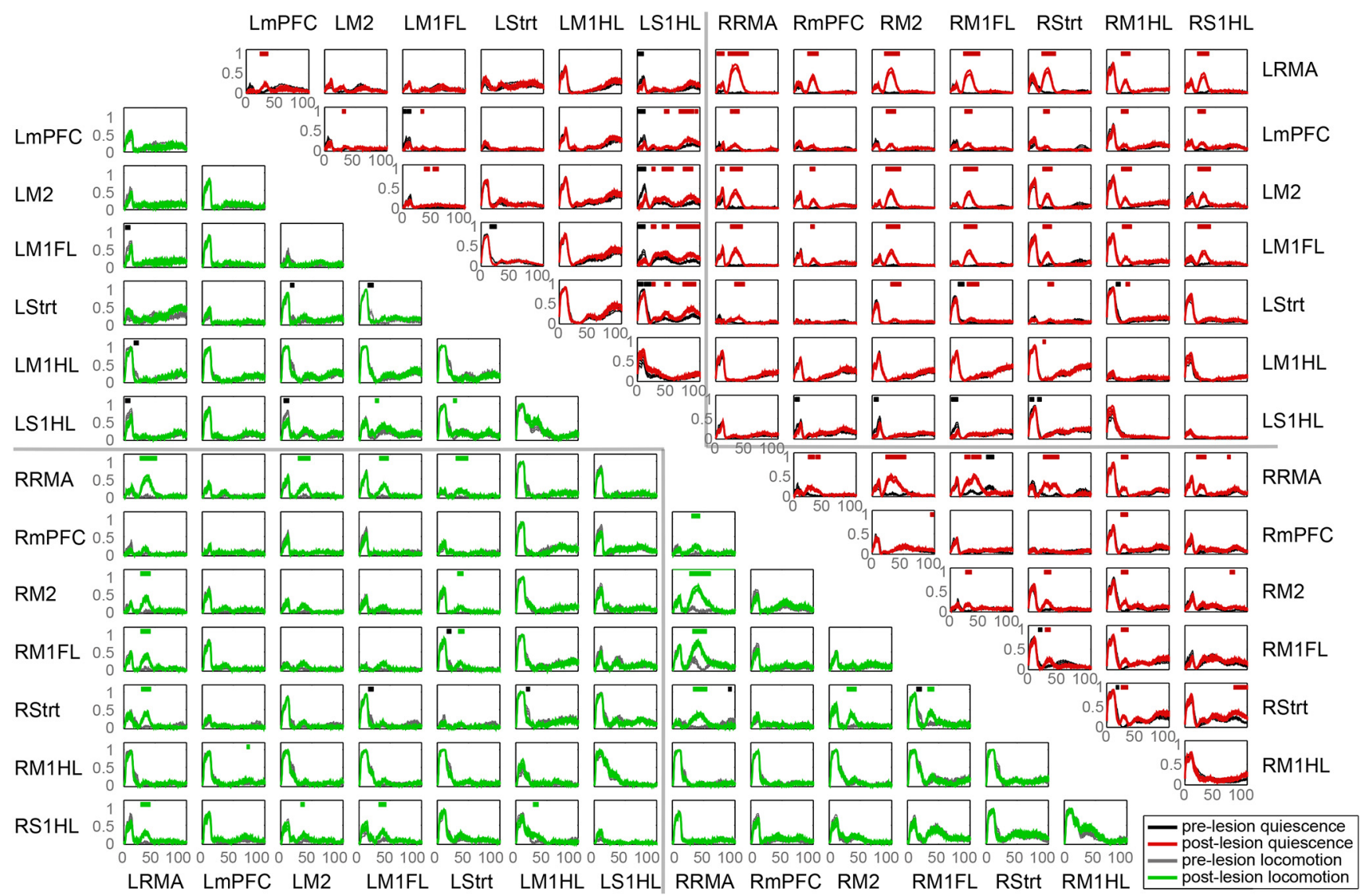

Figure 3. Interregional functional connectivity changes after the 6-OHDA lesion. PLI for prelesion and postlesion conditions per region pair. Quiescent state connectivity in prelesion (black) and postlesion (red) conditions are to the right of the diagonal. Locomotion-related connectivity in prelesion (gray), and postlesion (green) conditions is shown to the left of the diagonal. Horizontal red and green bars indicate frequencies of significantly increased connectivity for quiescence and locomotion, respectively. Black bars indicate frequencies of significantly decreased connectivity $(p<0.05)$

power as to be larger during quiescence than locomotion in the lesioned hemisphere (Fig. 2; $p=0.0711$ for interaction lesion $\times$ behavior, $2 \times 2$ ANOVA, $p=0$ for main effect of lesion). Thus, dopamine cell loss led to an increase in beta power in many cortical areas and the dorsolateral striatum of the lesioned hemisphere, especially during quiescence.

6-OHDA-induced changes in LFP-LFP phase synchronization Next, we used a symmetric, nondirected measure of connectivity, namely, the PLI (see Materials and Methods) to study how nigrostriatal dopamine cell loss altered functional connectivity between brain areas. We computed the PLI for all possible combinations of the 14 recorded brain areas (Figs. 3, 4). Both during quiescence and locomotion, we observed that dopamine cell loss induced significant increases in PLI predominantly in the beta frequencies (Figs. 3, 4). We observed an increase in beta PLI for many area combinations within the lesioned hemisphere, whereas we did not observe this for the nonlesioned hemisphere (Figs. 3, 4). Further, we observed a significant increase in beta PLI between the two hemispheres, especially for pairs of areas in which at least one area was a more rostral cortical area (Figs. 3, 4). In summary, we found a strong increase in beta interhemispheric coupling and beta coupling within the lesioned hemisphere after nigrostriatal dopamine depletion.

\section{Alterations in directed influences within the lesioned hemisphere}

The coherence analysis revealed prominent changes in functional connectivity among sites within the lesioned, but not within the nonlesioned, hemisphere (Fig. 3). A change in beta connectivity between two areas (e.g., area R-RMA and R-M1FL) could reflect symmetric increases in directed influences (i.e., similar changes in directed influences from area R-RMA to R-M1FL and area R-M1FL to R-RMA). Alternatively, it might reflect asymmetric changes in directed influences among brain areas (e.g., a larger increase in the directed influence from area R-RMA to R-M1FL than from area R-M1FL to R-RMA).

To test for this, we performed a spectral GC analysis for all different area combinations separately. For each pair of areas and each frequency, this analysis yielded a directed influence from area 1 to area 2 (e.g., R-RMA $\rightarrow$ RM1FL), but also from area 2 to area 1 (e.g., RM1FL $\rightarrow$ R-RMA) (Figs. 5, 6). To quantify the extent to which an area tends to be a "driver" or a "receiver" with respect to another area, we computed the DAI (see Materials and Methods) (Bastos et al., 2015), defined as $\left[\mathrm{GC}_{\text {in }}-\mathrm{GC}_{\text {out }}\right]$ / $\left[\mathrm{GC}_{\text {in }}+\mathrm{GC}_{\text {out }}\right]$ where GC stands for GC influence. The DAI ranges between -1 and 1 , with 0 indicating symmetric interactions, DAI 1 indicating that an area is only a "receiver," and DAI -1 indicating that an area is only a "driver." The DAI values were first computed for each area combination separately. For a given area, we then averaged its DAI values by averaging across all the combinations with the other areas (see Materials and Methods). The pattern of directed influences from and to the other brain areas defines the hierarchical position of an area in the network. If an area had a high average DAI value, then it was positioned at a high hierarchical level (i.e., receiving many GC influences), whereas a low average 

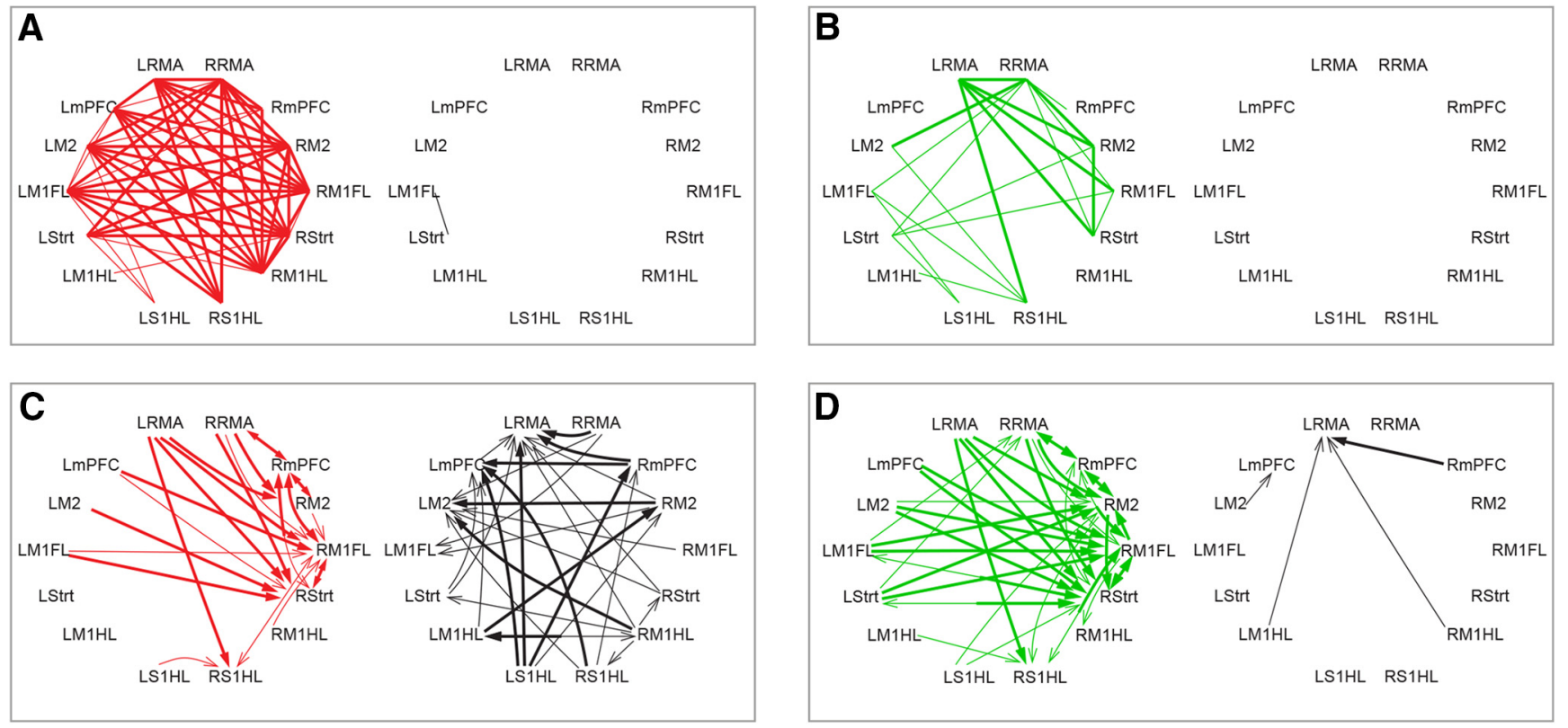

Figure 4. Spatial representation of functional connectivity and GC changes in the beta frequencies. Significantly increased (red/green in conditions sit/walk, respectively) and decreased (black) functional connectivity plotted for sit $(\boldsymbol{A})$ and walk $(\boldsymbol{B})$ conditions in the top row. Bottom row represents significant changes in $\mathrm{GC}$ after the 6-0HDA lesion in the two behavioral conditions $(C, D)$. Thin/thick lines and arrows indicate extent of significant changes whenever present for $>5 \mathrm{~Hz} / 10 \mathrm{~Hz}$ wide, respectively.

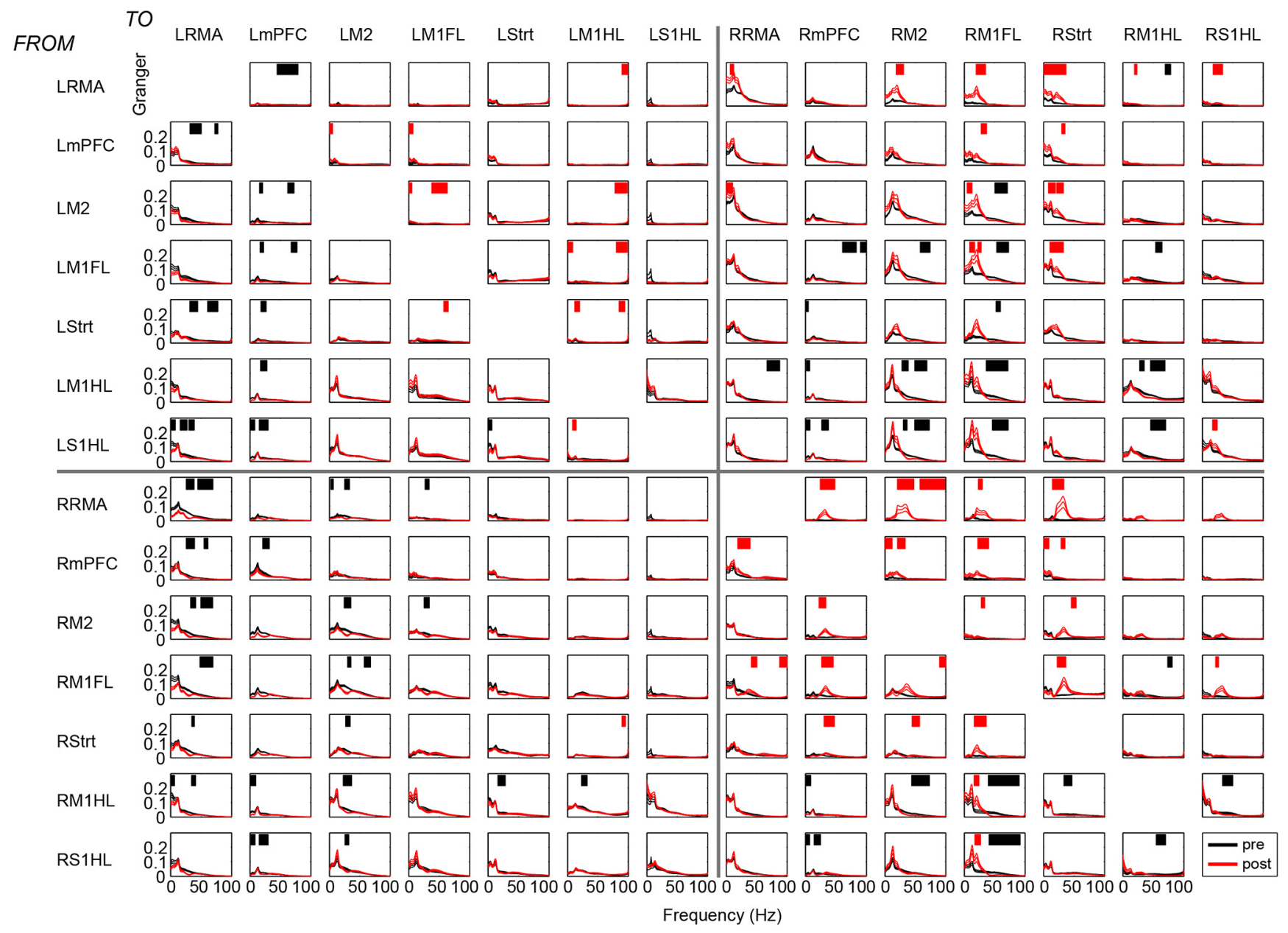

Figure 5. Interregional GC changes during quiescence before and after 6-OHDA lesion. GC spectra for prelesion (black) and postlesion (red) conditions per region pair. Red bars indicate frequencies of significantly increased GC influence. Black bars indicate frequencies of significantly decreased GC influence $(p<0.05)$. 


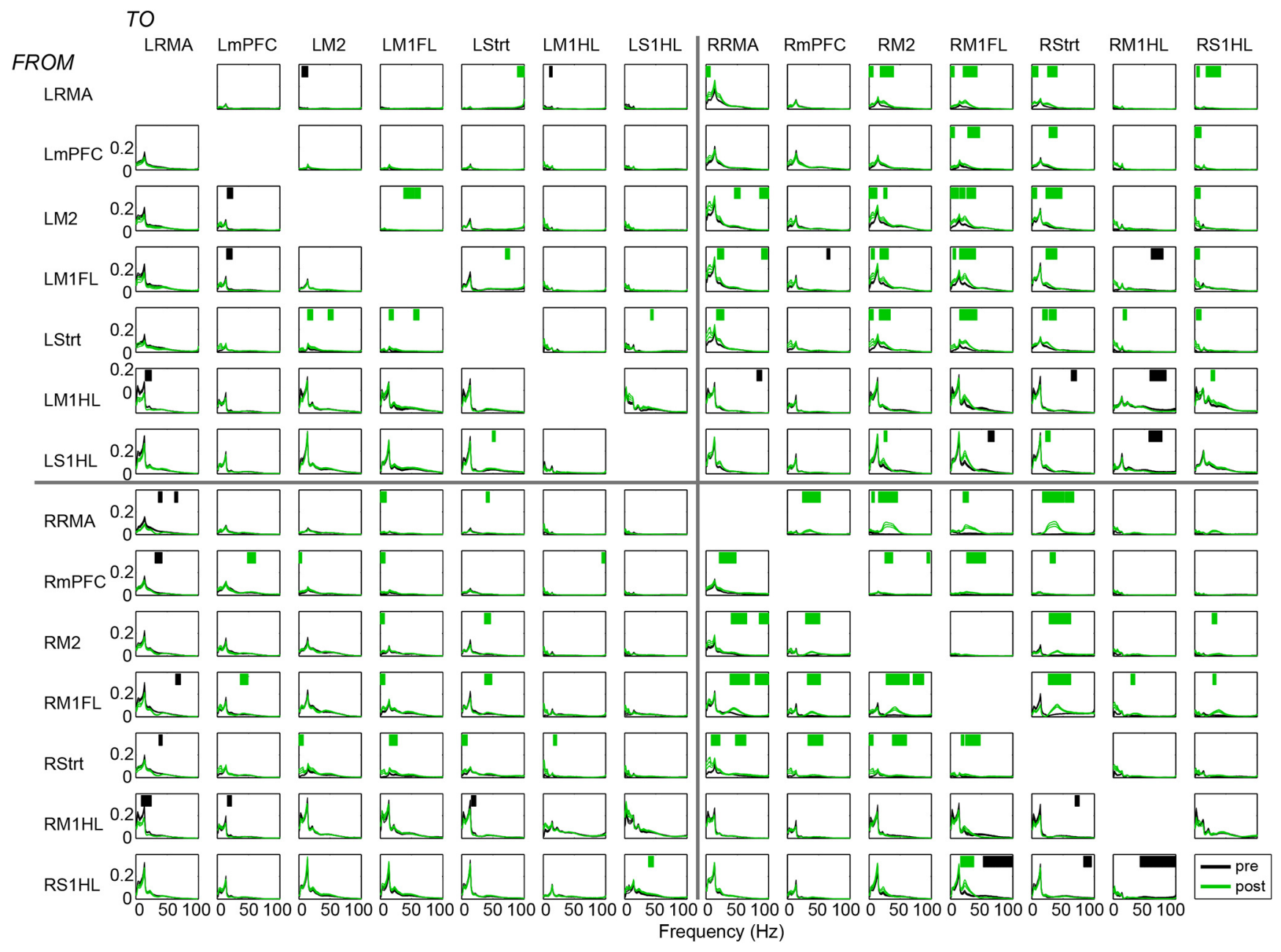

Figure 6. Interregional GC changes during locomotion before and after 6-OHDA lesion. GC spectra for prelesion (black) and postlesion (green) conditions per region pair. Horizontal green bars indicate frequencies of significantly increased $\mathrm{GC}$ influence. Black bars indicate frequencies of significantly decreased $\mathrm{GC}$ influence $(p<0.05)$.

DAI value indicated that it was positioned at a low hierarchical level. Previously, Bastos et al. (2015) and Michalareas et al. (2016) have shown that, within the occipitoparietal cortex of primates, DAI values show very good overlap with anatomically based measures of hierarchy (Markov et al., 2014).

We found that, before the 6-OHDA lesion, there was a strong hierarchical organization in which some areas tended to be "drivers," whereas other areas tended to be "receivers" (Fig. 7). Areas that were located more rostrally tended to be located at the top of the hierarchy (i.e., "receivers"), whereas areas located more caudally tended to be located at the bottom of the hierarchy (i.e., "drivers"). We found that the hierarchical ranking of areas was well preserved between quiescence and locomotion conditions (Fig. 7).

We further found that the 6-OHDA lesion caused a profound change in the hierarchical organization of neuronal interactions in the beta frequency-band. The more rostral areas that were positioned at the top of the hierarchy before the lesion showed a decrease in their hierarchical level after the lesion (i.e., a decrease in average DAI). Conversely, the more caudal areas that were positioned at the bottom of the hierarchy before the lesion increased their hierarchical level after the lesion (i.e., increase in average DAI) (Fig. 7A). This pattern of changes resulted in a strong negative correlation between an area's hierarchical level prelesion and the change in hierarchical level from prelesion to postlesion (Fig. $7 B$ ). The effect of these changes in DAI values was that the cortical hierarchy (see Materials and Methods) flattened after the 6-OHDA lesion (Fig. 7C).

The lesion-induced decrease in DAI values for areas at the top of the cortical hierarchy might correspond either to a reduction in GC inflow from other areas toward these areas or to an increase in GC outflow from these areas toward other areas. To disentangle these two scenarios, we computed the change in both GC in and outflow between prelesion and postlesion. We then correlated these change values with the prelesion hierarchical level (Fig. $7 D, E$ ). We found that the decrease in DAI values for the areas at the top of the hierarchy was caused by an increased directed influence onto the other areas, whereas the increase in DAI values for the other (more caudal) areas was caused by an increase in received GC influence (Fig. $7 D, E$ ).

We also found that the pattern of changes in directed influences was largely dissociated from changes in beta-oscillatory power. First, we found no significant correlation between the change in hierarchical level from prelesion to postlesion and the change in beta power from prelesion to postlesion $(r=-0.63$, $p=0.12$ for quiescence, $r=-0.65, p=0.11$ for locomotion). For example, areas RMA and M1FL both showed a prominent increase in beta-oscillatory activity (Fig. 2), whereas the GC influence strongly increased from R-RMA to R-M1FL (Figs. 5, 6). Second, we found similar changes in hierarchical ordering for the quiescence and locomotion condition (Fig. 7A), even though the 
A

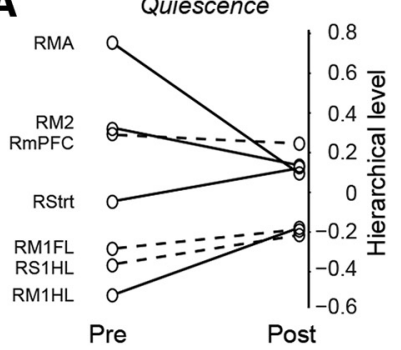

B
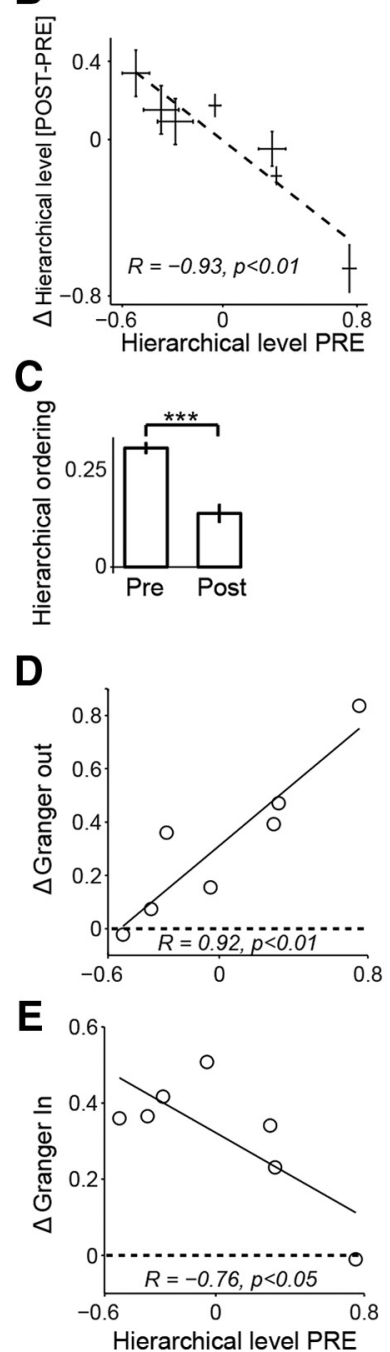
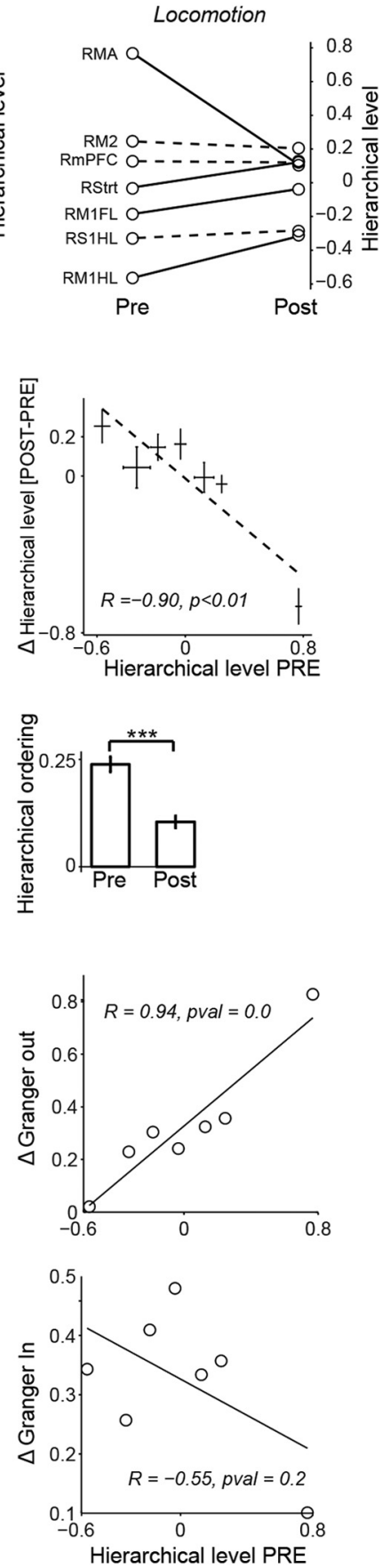

Figure 7. Changes in cortical hierarchy after 6-OHDA lesion. $A$, Hierarchical level for each brain area prelesion and postlesion during quiescence (left) and locomotion (right). Hierarchical level was computed as the average $\mathrm{DAl}$, which equals $\left[\mathrm{GC}_{\text {in }}-\mathrm{GC}_{\text {out }}\right] /\left[\mathrm{GC}_{\text {in }}+\mathrm{GC}_{\text {out }}\right]$ where $\mathrm{GC}$ is the $\mathrm{GC}$ influence. Solid lines indicate areas for which the hierarchical level showed a significant change postlesion (two-sample $t$ test, $p<0.05$ ). $\boldsymbol{B}$, Hierarchical level prelesion versus the change in hierarchical level from prelesion to postlesion. Left, Quiescence. Right, Locomotion. C, Hierarchical ordering of the network, which was quantified as the variance of the hierarchical levels across areas. Left, Quiescence. Right, Locomotion. $\boldsymbol{D}$, Change in $\mathrm{GC}$ outflow as a function of the prelesion hierarchical level. Areas at the top of the hierarchy increase their GC outflow. $E$, Change in GC inflow as a function of the prelesion hierarchical level. Areas at the top of the hierarchy tend to receive more $\mathrm{GC}$ inflow postlesion during quiescence, but not during locomotion. ${ }^{* * *} p<0.01$, Student's $t$-test.

beta power increase was more pervasive in the quiescence than in the locomotion condition (Fig. 2).

In sum, we conclude that dopaminergic cell loss leads to a marked alteration in cortical hierarchical organization, resulting in an increased drive from "top-down" frontal areas onto the primary motor and somatosensory regions.

\section{Alterations in directed interhemispheric influences}

Similar to the case of intrahemispheric influences, we asked whether the change in beta connectivity (PLI, Fig. 2) between the right (lesioned) and left (nonlesioned) hemisphere might reflect either a symmetric increase in interhemispheric influences or an asymmetric change in directed influences among the two hemispheres.

We observed that, both during quiescence and locomotion, there was a strong increase in the directed GC influence in the beta-band from the left to the right hemisphere (Figs. 4-6, 8A; $p=0.005$ for lesion, $p=0.384$ for state, $p=0.153$ for interaction state $\times$ lesion). However, we found that, only during quiescence, the directed influence from the lesioned to the nonlesioned hemisphere tended to decrease, whereas during locomotion, it did not change (Fig. $8 A$; two-way ANOVA, $p=0.0092, p=0.036$ for interaction state $\times$ lesion, main effect state, $p=0.98)$. The change in GC influence values between hemispheres occurred despite the fact that beta-band power was higher in the lesioned than the nonlesioned hemisphere (Fig. 2). Thus, we found that, similar to the case of change in directed influences within the lesioned hemisphere, there was dissociation between the pattern of beta-power changes and the change pattern of directed influence changes.

Similar to the analysis in Figure 7, we then computed DAI values to examine the pattern of directed influences across areas (see Materials and Methods). In this case, we first obtained a directed influence from area 1 to area 2 (e.g., L-RMA $\rightarrow$ R-M1FL), but also from area 2 to area 1 (e.g., R-M1FL $\rightarrow$ L-RMA). We then computed the DAI value for both areas, for example, $\left[\mathrm{GC}_{\mathrm{L}-\mathrm{RMA} \rightarrow \mathrm{RM} 1 \mathrm{FL}}-\mathrm{GC}_{\mathrm{RM} 1 \mathrm{FL} \rightarrow \mathrm{L}-\mathrm{RMA}}\right] /$ $\left[\mathrm{GC}_{\mathrm{L}-\mathrm{RMA} \rightarrow \mathrm{RM} 1 \mathrm{FL}}+\mathrm{GC}_{\mathrm{RM} 1 \mathrm{FL} \rightarrow \mathrm{L}-\mathrm{RMA}}\right]$. We then obtained a single average DAI value for each area in the left hemisphere by averaging these DAI values across all combinations with areas in the right hemisphere. A high DAI value indicates that an area in the left tended to receive strong GC influences from the areas in the right hemisphere.

We found that the changes in directed influences from prelesion to postlesion showed substantial area specificity, similar to the analysis of symmetric connectivity. In particular, directed influences from the more rostral, nonprimary frontal areas in the left hemisphere toward areas in the right hemisphere tended to increase (Fig. $8 B$ ). These areas were positioned at the top of the hierarchy both within each hemisphere, but also with respect to the interhemispheric interactions (Fig. 8B). This resulted in a strong linear correlation between the prelesion hierarchical level and the change in DAI (Fig. $8 B$ ).

Together, these findings show that the increase in functional connectivity between hemispheres indeed reflects asymmetric changes in directed influences. Quiescence, but not locomotion, was characterized by a reduction of directed influence from the right to the left hemisphere. Directed influences toward the right hemisphere tended to increase, especially for those areas in the left hemisphere that were positioned higher in the cortical hierarchy (RMA, mPFC, M2).

\section{Discussion}

Increased local oscillatory activity in the high beta-low gamma frequencies was observed in multiple brain areas in both the lesioned and unlesioned hemispheres of the hemiparkinsonian rat model. We present three main findings. First, in the prelesioned state, we established a functional hierarchy in cortical organiza- 
A

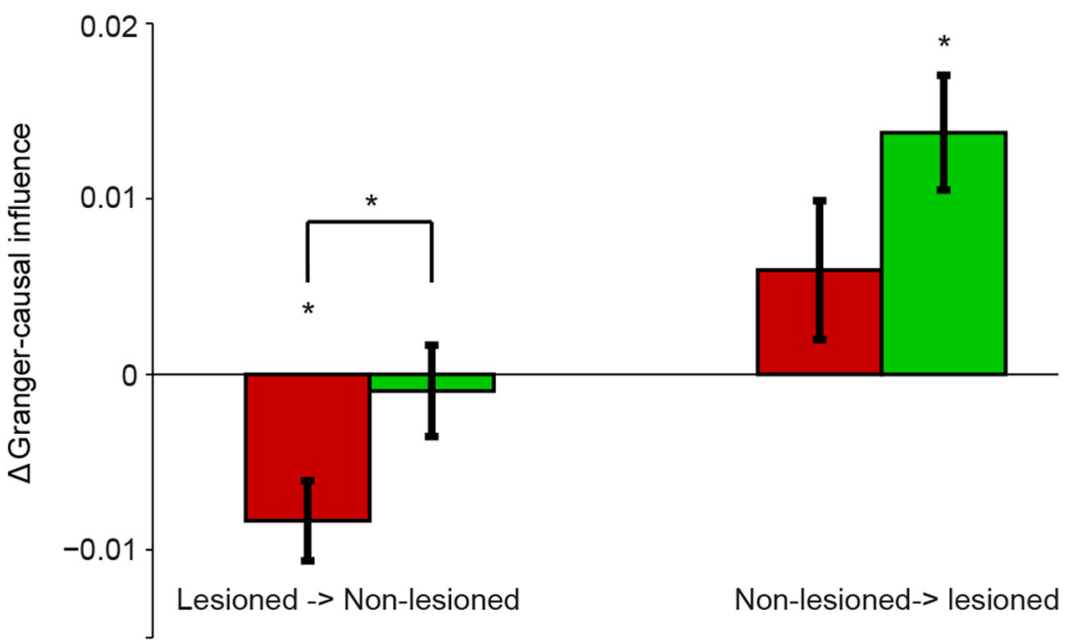

B
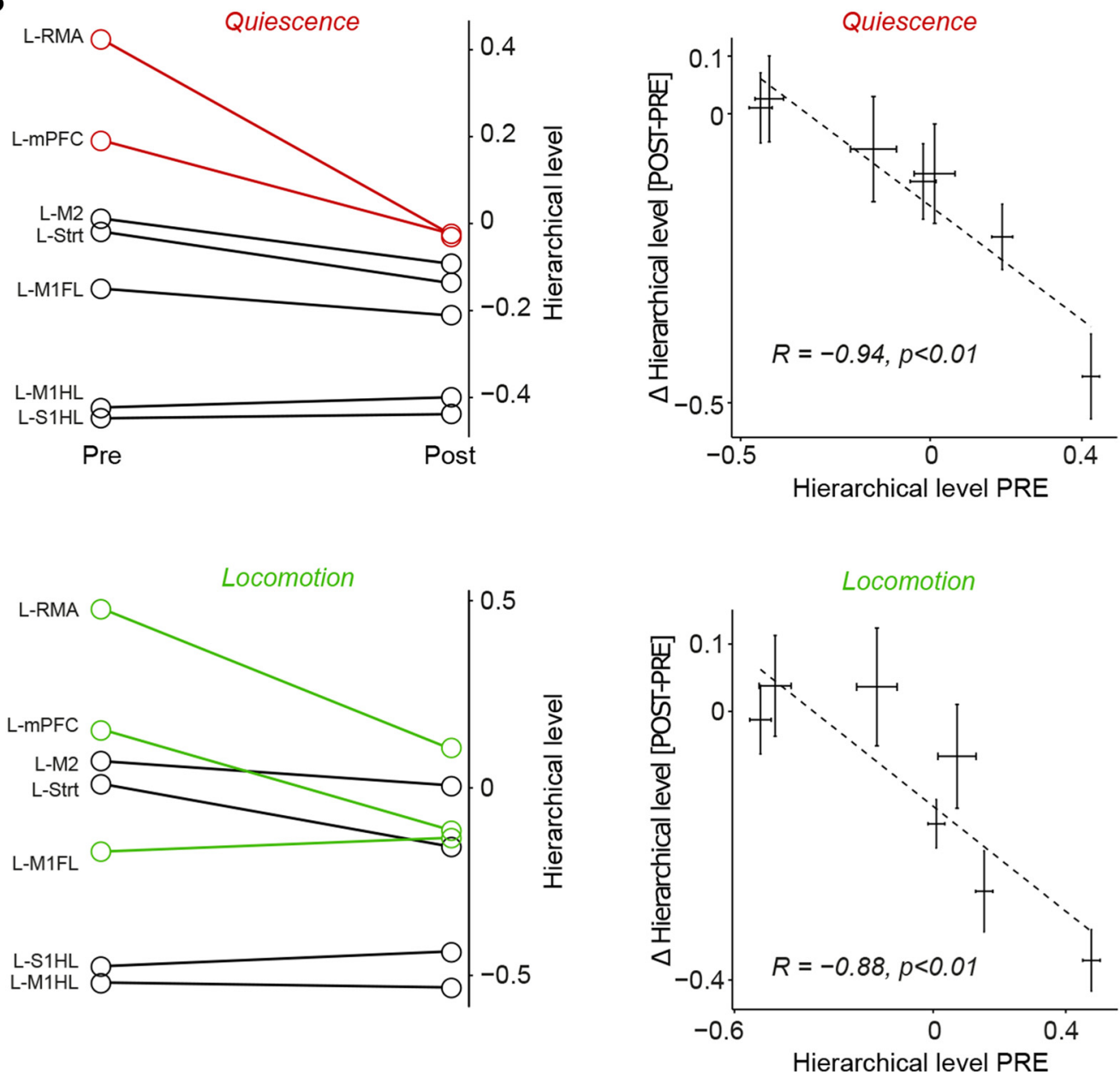

Figure 8. Changes in interhemispheric interactions after 6-OHDA lesion. $A$, Change in $\mathrm{GC}$ influence from lesioned to nonlesioned and nonlesioned to lesioned hemisphere (see Materials and Methods), separately for locomotion (green) and quiescence (red). $\boldsymbol{B}$, Left, Changes in GC influence, expressed as a difference in DAl values, between prelesion and postlesion conditions. Red and green lines indicate areas for which the hierarchical level showed a significant change postlesion (two-sample $t$ test, $p<0.05$ ), separately for quiescence and locomotion, in 20 - $40 \mathrm{~Hz}$ band. Right, Hierarchical level prelesion versus the change in hierarchical level from prelesion to postlesion. Top, Quiescence. Bottom, locomotion. ${ }^{*} p<0.05$, two-way ANOVA (main effect), or Student's $t$-test.

tion. Second, an increased directional influence from the nonlesioned toward the lesioned hemisphere was found in the "beta" frequencies in both rest and walk conditions. Third, cortical areas that were positioned higher in the hierarchy tended to increase their directed influence on areas positioned lower in the hierar- chy after unilateral dopamine cell loss. This only occurred in the lesioned hemisphere.

The present findings are consistent with increased betaoscillatory activity in the basal ganglia and cortex of the rodent model (Mallet et al., 2008; Degos et al., 2009; Brazhnik et al., 2012; 
Q. Li et al., 2012, M. Li et al., 2016) and asymmetric appearance of the beta peak (Q. Li et al., 2012). Furthermore, our observation of increased interregional coupling in the beta band confirms previous corticocortical and corticosubcortical functional connectivity results obtained in the unilateral 6-OHDA model (Degos et al., 2009; Brazhnik et al., 2012, 2016; Jávor-Duray et al., 2015; M. Li et al., 2016). The GC analysis of the present data showed bidirectional influences with corticostriatal predominance, which is consistent with findings in rodents (Nakhnikian et al., 2014; Belić et al., 2016) and with increased corticobasal ganglia directionality as observed in Parkinson patients (Lalo et al., 2008; Litvak et al., 2012; Kato et al., 2015; Oswal et al., 2016).

Concerning GC, our findings of the lesioned hemisphere lagging behind the nonlesioned hemisphere in the beta frequencies are in line with data in Parkinson patients showing a greater delay of premovement suppression of beta activity in the hemisphere most affected by nigral dopaminergic cell loss (Defebvre et al., 1996; Alegre et al., 2005). For the subthalamic nucleus, the latter observations have been suggested to represent bilateral control over single-sided movement, and the present results are likely related to a similar process (Alegre et al., 2005).

With respect to hierarchical influences, in the prelesion condition, we found that $\mathrm{mPFC}$, the rostral motor area, and M2 were at the top of the cortical hierarchy, whereas the primary motor regions were at a lower place, similar to information flow patterns in human subjects (Hillebrand et al., 2016). Our approach for establishing a hierarchical organization has previously been shown to correlate very well with structured connectivity patterns demonstrating anatomical hierarchy among visual, parietal, and frontal areas (Bastos et al., 2015, Michalareas et al., 2016). Indeed, the present findings correspond well with structural connectivity because strong reciprocal connections exist between the prefrontal cortex, the rostral motor area, and the more caudal portions of M1 (Bedwell et al., 2014). Such a functional and structural hierarchical organization comprising the motor system is in accordance with a recently proposed functional framework encompassing the entire primate cortex on the basis of anatomical measurements of hierarchy (i.e., structural connectivity determined by tracing intracortical connections) (Chaudhuri et al., 2015). The lower hierarchical position of S1 hindlimb area (S1) and M1 that was found in the present study is consistent with the organization described for the visual and motor systems (Markov et al., 2014; Bastos et al., 2015; Chaudhuri et al., 2015; Michalareas et al., 2016). It puts M1 and S1 low in the hierarchy, almost at the same level as V1. This might seem surprising given that $\mathrm{M} 1$ is the main output of corticospinal projections, but it is likely that the anterior cortical areas exert modulatory influences over M1, while M1 exerts strong driving influences over these areas (see below). Thus, our data suggest that, in normal conditions, the anteriorly located areas are situated higher in the hierarchy, that they are primarily driven by the more caudal portions of M1, and that they in turn exert modulatory control of the primary motor cortex.

The 6-OHDA lesions in the present experiments led to a disruption of network hierarchy. Although the following conclusions are based on findings in cortex and therefore focus on the cortical network, a note of caution is in order because it cannot be ruled out that changes in GC between two cortical regions are influenced by a "third driver," for instance, the thalamus (Sherman and Guillery, 2011). If we restrict our conclusions to cortex, while bearing in mind the above reservations, the present data suggest a flattening of cortical network hierarchy. With respect to interhemispheric interactions, it went from symmetric to asym- metric, whereas for intrahemispheric interactions, it went from a strongly asymmetric to a more symmetric functional hierarchy. We found that, after the lesion, the areas at the top of the hierarchy assumed the same hierarchical position as the other areas, which led to a more bidirectional pattern of communication among the areas. The change in hierarchical ordering primarily came from an increase in drive from the higher-ranking areas, rather than a loss of drive from areas lower in the cortical hierarchy. These changes were largely independent of changes in betaoscillatory power, as the nonlesioned hemisphere showed less beta-oscillatory activity and there was no correlation between the hierarchical level and power changes in the beta band. Thus, our findings appear to reveal a new aspect of cortical interactions orthogonal to the increase in beta-oscillatory power. The orthogonality of both had already been established by Jávor-Duray et al. (2015), who showed that coupling increases much earlier than the increase in beta-oscillatory power.

Finally, we found that the above processes tended to occur both during locomotion and quiescence, suggesting a plastic reorganization of cortical interactions rather than transient activation patterns occurring only during specific behaviors (Schwab et al., 2013; Brazhnik et al., 2014; Deffains and Bergman, 2015). A new state of interactions is supported by recent findings on the role of striatal dopaminergic axons in the exquisite timing of motor activity (Howe and Dombeck, 2016). These refined processes are possibly represented in our results on causal influences. We did find, however, that during locomotion, there was no decrease of causal influences from the lesioned to nonlesioned hemisphere, showing some state dependence of the observed patterns.

What are the functional implications of these findings? We propose two possible scenarios. In the first scenario, the observed changes are (directly) incurred by the dopamine depletion leading to inefficient signaling in cortex and basal ganglia (Beeler et al., 2013). The second scenario views the changes in directed interactions as compensatory. Under this account, the equilibrium of the system in the dopamine-depleted state is characterized by a stronger influence from the nonlesioned hemisphere toward the lesioned hemisphere, which is also related to motor activity. Consistent with this, in Parkinson's disease patients, a stronger activation of the less affected hemisphere is present during unilateral motor activity than in healthy controls (Wu et al., 2015b). Furthermore, motor disturbances in asymmetrically dopamine-depleted rats appear later than in symmetrically lesioned cases (Degos et al., 2009), possibly as a consequence of interhemispheric interactions, such as the changes in directionality observed in the present study.

In the framework of predictive coding in the motor system, "action minimizes proprioceptive prediction errors," relying heavily on the accuracy of the prediction errors (Friston et al., 2012). The reconfiguration of the functional network (hierarchy) as observed in the present study, with areas higher in the cortical hierarchy increasing their control of the primary areas within the lesioned hemisphere, would be brought about by unreliable prediction errors, as a consequence of dopamine depletion (Friston et al., 2012; Adams et al., 2013; Shipp et al., 2013; Colder, 2015). In an overarching view of dopamine function, encompassing (among many other roles) dopamine's role in reward prediction error, Friston et al. (2012) proposed that fluctuating levels of dopamine signal changes in the precision of prediction errors (i.e., the reliability of proprioceptive information in action selection). Modeling changes in accuracy of prediction errors (simulating dopamine lesions) has been shown to induce parkinsonian 
behavioral symptoms (Friston et al., 2012). Unreliable prediction errors in Parkinson's disease will lead to behavioral deficits and make patients more reliant on top-down prediction (Friston et al., 2012; Galea et al., 2012); in other words, this might lead to the higher cortical areas attempting to control the areas lower in the cortical hierarchy (Galea et al., 2012). Basal ganglia malfunction will further exacerbate errors in predictive coding (Colder, 2015).

The state of top-down control resembles that in the early stages of learning a motor task, when initial top-down cortical control, from frontal and cingulate areas to sensorimotor system, is lost over time as task execution becomes automated (Bassett et al., 2015). Interestingly, in Parkinson's disease, there is a greater reduction in automated movement than intended voluntary movement (for review, see Wu et al., 2015a). Automatic motor behavior is associated with reduced activity in the nonprimary frontal motor areas and reduced connectivity to motor areas $(\mathrm{Wu}$ et al., 2015a). However, in Parkinson's disease, motor skills revert to the early learning stage (Bassett et al., 2015; Wu et al., 2015a). Thus, if Parkinson's disease puts patients permanently in the initial learning stage, more top-down control might be recruited to compensate for this.

The current study provides new insight into the interhemispheric dynamics in the asymmetrically dopamine-depleted brain that may be of relevance to Parkinson's disease patients, many of whom initially display asymmetrical nigral degeneration before generalization to both sides of the brain (Scherfler et al., 2012). Our results provide evidence for an increased drive from the nonlesioned toward the lesioned hemisphere (in particular to striatum), most prominently during walking, suggesting a compensatory influence exerted by the nonlesioned side on the hemisphere with lesion-induced basal ganglia dysfunction. The lesion-induced change in symmetric functional connectivity involved a profound reorganization of hierarchical organization and directed influence patterns. In the lesioned hemisphere, nonprimary motor areas at the top of the cortical hierarchy increased their directed influence onto the primary motor and somatosensory areas, which may represent a compensatory mechanism for loss of motor automaticity as a consequence of dopamine depletion.

\section{References}

Adams RA, Shipp S, Friston KJ (2013) Predictions not commands: active inference in the motor system. Brain Struct Funct 218:611-643. CrossRef Medline

Alegre M, Alonso-Frech F, Rodríguez-Oroz MC, Guridi J, Zamarbide I, Valencia M, Manrique M, Obeso JA, Artieda J (2005) Movement-related changes in oscillatory activity in the human subthalamic nucleus: ipsilateral vs contralateral movements. Eur J Neurosci 22:2315-2324. CrossRef Medline

Bassett DS, Yang M, Wymbs NF, Grafton ST (2015) Learning-induced autonomy of sensorimotor systems. Nat Neurosci 18:744-751. CrossRef Medline

Bastos AM, Vezoli J, Bosman CA, Schoffelen JM, Oostenveld R, Dowdall JR, De Weerd P, Kennedy H, Fries P (2015) Visual areas exert feedforward and feedback influences through distinct frequency channels. Neuron 85:390-401. CrossRef Medline

Bedwell SA, Billett EE, Crofts JJ, Tinsley CJ (2014) The topology of connections between rat prefrontal, motor and sensory cortices. Front Syst Neurosci 8:177. CrossRef Medline

Beeler JA, Petzinger G, Jakowec MW (2013) The enemy within: propagation of aberrant corticostriatal learning to cortical function in Parkinson's disease. Front Neurol 4:134. CrossRef Medline

Belić JJ, Halje P, Richter U, Petersson P, Hellgren Kotaleski J (2016) Untangling cortico-striatal connectivity and cross-frequency coupling in L-DOPAinduced dyskinesia. Front Syst Neurosci 10:26. CrossRef Medline

Brazhnik E, Cruz AV, Avila I, Wahba MI, Novikov N, Ilieva NM, McCoy AJ, Gerber C, Walters JR (2012) State-dependent spike and local field syn- chronization between motor cortex and substantia nigra in hemiparkinsonian rats. J Neurosci 32:7869-7880. CrossRef Medline

Brazhnik E, Novikov N, McCoy AJ, Cruz AV, Walters JR (2014) Functional correlates of exaggerated oscillatory activity in basal ganglia output in hemiparkinsonian rats. Exp Neurol 261:563-577. CrossRef Medline

Brazhnik E, McCoy AJ, Novikov N, Hatch CE, Walters JR (2016) Ventral medial thalamic nucleus promotes synchronization of increased high beta-oscillatory activity in the basal ganglia-thalamocortical network of the hemiparkinsonian rat. J Neurosci 36:4196-4208. CrossRef Medline

Chaudhuri R, Knoblauch K, Gariel MA, Kennedy H, Wang XJ (2015) A large-scale circuit mechanism for hierarchical dynamical processing in the primate cortex. Neuron 88:419-431. CrossRef Medline

Colder B (2015) The basal ganglia select the expected sensory input used for predictive coding. Front Comput Neurosci 9:119. CrossRef Medline

Dauwan M, van Dellen E, van Boxtel L, van Straaten EC, de Waal H, Lemstra AW, Gouw AA, van der Flier WM, Scheltens P, Sommer IE, Stam CJ (2016) EEG-directed connectivity from posterior brain regions is decreased in dementia with Lewy bodies: a comparison with Alzheimer's disease and controls. Neurobiol Aging 41:122-129. CrossRef Medline

Defebvre L, Bourriez JL, Destée A, Guieu JD (1996) Movement related desynchronisation pattern preceding voluntary movement in untreated Parkinson's disease. J Neurol Neurosurg Psychiatry 60:307-312. CrossRef Medline

Deffains M, Bergman H (2015) Striatal cholinergic interneurons and cortico-striatal synaptic plasticity in health and disease. Mov Disord 30: 1014-1025. CrossRef Medline

Degos B, Deniau JM, Chavez M, Maurice N (2009) Chronic but not acute dopaminergic transmission interruption promotes a progressive increase in cortical beta frequency synchronization: relationships to vigilance state and akinesia. Cereb Cortex 19:1616-1630. CrossRef Medline

Dejean C, Nadjar A, Le Moine C, Bioulac B, Gross CE, Boraud T (2012) Evolution of the dynamic properties of the cortex-basal ganglia network after dopaminergic depletion in rats. Neurobiol Dis 46:402-413. CrossRef Medline

Dhamala M, Rangarajan G, Ding M (2008) Estimating Granger causality from Fourier and wavelet transforms of time series data. Phys Rev Lett 100:18701. CrossRef Medline

Donoghue JP, Wise SP (1982) The motor cortex of the rat: cytoarchitecture and microstimulation mapping. J Comp Neurol 212:76-88. CrossRef Medline

Fries P, Womelsdorf T, Oostenveld R, Desimone R (2008) The effects of visual stimulation and selective visual attention on rhythmic neuronal synchronization in macaque area V4. J Neurosci 28:4823-4835. CrossRef Medline

Friston KJ, Shiner T, FitzGerald T, Galea JM, Adams R, Brown H, Dolan RJ, Moran R, Stephan KE, Bestmann S (2012) Dopamine, affordance and active inference. PLoS Comput Biol 8:e1002327. CrossRef Medline

Galea JM, Bestmann S, Beigi M, Jahanshahi M, Rothwell JC (2012) Action reprogramming in Parkinson's disease: response to prediction error is modulated by levels of dopamine. J Neurosci 32:542-550. CrossRef Medline

Gioanni Y, Lamarche M (1985) A reappraisal of rat motor cortex organization by intracortical microstimulation. Brain Res 344:49-61. CrossRef Medline

Groenewegen H, Voorn P, Scheel-Kruger J (2016) Limbic basal ganglia circuits: parallel and integrative aspects. In: The basal ganglia: novel perspectives on motor and cognitive functions. New York: Springer.

Haufe S, Nikulin VV, Müller KR, Nolte G (2013) A critical assessment of connectivity measures for EEG data: a simulation study. Neuroimage 64:120-133. CrossRef Medline

Helmich RC, Derikx LC, Bakker M, Scheeringa R, Bloem BR, Toni I (2010) Spatial remapping of cortico-striatal connectivity in Parkinson's disease. Cereb Cortex 20:1175-1186. CrossRef Medline

Hillebrand A, Tewarie P, van Dellen E, Yu M, Carbo EW, Douw L, Gouw AA, van Straaten EC, Stam CJ (2016) Direction of information flow in largescale resting-state networks is frequency-dependent. Proc Natl Acad Sci U S A 113:3867-3872. CrossRef Medline

Howe MW, Dombeck DA (2016) Rapid signalling in distinct dopaminergic axons during locomotion and reward. Nature 535:505-510. CrossRef Medline

Jávor-Duray BN, Vinck M, van der Roest M, Mulder AB, Stam CJ, Berendse HW, Voorn P (2015) Early-onset cortico-cortical synchronization in 
the hemiparkinsonian rat model. J Neurophysiol 113:925-936. CrossRef Medline

Kato K, Yokochi F, Taniguchi M, Okiyama R, Kawasaki T, Kimura K, Ushiba J (2015) Bilateral coherence between motor cortices and subthalamic nuclei in patients with Parkinson's disease. Clin Neurophysiol 126:19411950. CrossRef Medline

Lalo E, Thobois S, Sharott A, Polo G, Mertens P, Pogosyan A, Brown P (2008) Patterns of bidirectional communication between cortex and basal ganglia during movement in patients with Parkinson disease. J Neurosci 28 : 3008-3016. CrossRef Medline

Li M, Zhou M, Wen P, Wang Q, Yang Y, Xiao H, Xie Z, Li X, Wang N, Wang J, Luo F, Chang J, Zhang W (2016) The network of causal interactions for beta oscillations in the pedunculopontine nucleus, primary motor cortex, and subthalamic nucleus of walking parkinsonian rats. Exp Neurol 282:27-36. CrossRef Medline

Li Q, Ke Y, Chan DC, Qian ZM, Yung KK, Ko H, Arbuthnott GW, Yung WH (2012) Therapeutic deep brain stimulation in Parkinsonian rats directly influences motor cortex. Neuron 76:1030-1041. CrossRef Medline

Litvak V, Eusebio A, Jha A, Oostenveld R, Barnes G, Foltynie T, Limousin P, Zrinzo L, Hariz MI, Friston K, Brown P (2012) Movement-related changes in local and long-range synchronization in Parkinson's disease revealed by simultaneous magnetoencephalography and intracranial recordings. J Neurosci 32:10541-10553. CrossRef Medline

Lovinger DM (2010) Neurotransmitter roles in synaptic modulation, plasticity and learning in the dorsal striatum. Neuropharmacology 58:951961. CrossRef Medline

Mallet N, Pogosyan A, Sharott A, Csicsvari J, Bolam JP, Brown P, Magill PJ (2008) Disrupted dopamine transmission and the emergence of exaggerated beta oscillations in subthalamic nucleus and cerebral cortex. J Neurosci 28:4795-4806. CrossRef Medline

Mao T, Kusefoglu D, Hooks BM, Huber D, Petreanu L, Svoboda K (2011) Long-range neuronal circuits underlying the interaction between sensory and motor cortex. Neuron 72:111-123. CrossRef Medline

Markov NT, Vezoli J, Chameau P, Falchier A, Quilodran R, Huissoud C, Lamy C, Misery P, Giroud P, Ullman S, Barone P, Dehay C, Knoblauch K, Kennedy H (2014) Anatomy of hierarchy: feedforward and feedback pathways in macaque visual cortex. J Comp Neurol 522:225-259. CrossRef Medline

Michalareas G, Vezoli J, van Pelt S, Schoffelen JM, Kennedy H, Fries P (2016) Alpha-beta and gamma rhythms subserve feedback and feedforward influences among human visual cortical areas. Neuron 89:384-397. CrossRef Medline

Michely J, Volz LJ, Barbe MT, Hoffstaedter F, Viswanathan S, Timmermann L, Eickhoff SB, Fink GR, Grefkes C (2015) Dopaminergic modulation of motor network dynamics in Parkinson's disease. Brain 138:664-678. CrossRef Medline

Mostile G, Nicoletti A, Dibilio V, Luca A, Pappalardo I, Giuliano L, Cicero CE, Sciacca G, Raciti L, Contrafatto D, Bruno E, Sofia V, Zappia M (2015) Electroencephalographic lateralization, clinical correlates and pharmacological response in untreated Parkinson's disease. Parkinsonism Relat Disord 21:948-953. CrossRef Medline

Nakhnikian A, Rebec GV, Grasse LM, Dwiel LL, Shimono M, Beggs JM (2014) Behavior modulates effective connectivity between cortex and striatum. PLoS One 9:e89443. CrossRef Medline

Neafsey EJ, Bold EL, Haas G, Hurley-Gius KM, Quirk G, Sievert CF, Terreberry RR (1986) The organization of the rat motor cortex: a microstimulation mapping study. Brain Res 396:77-96. CrossRef Medline

Oostenveld R, Fries P, Maris E, Schoffelen JM (2011) FieldTrip: open source software for advanced analysis of MEG, EEG, and invasive electrophysiological data. Comput Intell Neurosci 2011:156869. CrossRef Medline

Oswal A, Beudel M, Zrinzo L, Limousin P, Hariz M, Foltynie T, Litvak V, Brown P (2016) Deep brain stimulation modulates synchrony within spatially and spectrally distinct resting state networks in Parkinson's disease. Brain 139:1482-1496. CrossRef Medline

Palmer SJ, Ng B, Abugharbieh R, Eigenraam L, McKeown MJ (2009) Motor reserve and novel area recruitment: amplitude and spatial characteristics of compensation in Parkinson's disease. Eur J Neurosci 29:2187-2196. CrossRef Medline

Paxinos G, Watson C (2005) The rat brain in stereotaxic coordinates: the new coronal set, Ed 5. San Diego: Academic.

Pollok B, Kamp D, Butz M, Wojtecki L, Timmermann L, Südmeyer M, Krause V, Schnitzler A (2013) Increased SMA-M1 coherence in Parkinson's disease: pathophysiology or compensation? Exp Neurol 247:178-181. CrossRef Medline

Sabatini U, Boulanouar K, Fabre N, Martin F, Carel C, Colonnese C, Bozzao L, Berry I, Montastruc JL, Chollet F, Rascol O (2000) Cortical motor reorganization in akinetic patients with Parkinson's disease: a functional MRI study. Brain 123:394-403. CrossRef Medline

Scherfler C, Seppi K, Mair KJ, Donnemiller E, Virgolini I, Wenning GK, Poewe W (2012) Left hemispheric predominance of nigrostriatal dysfunction in Parkinson's disease. Brain 135:3348-3354. CrossRef Medline

Schwab BC, Heida T, Zhao Y, Marani E, van Gils SA, van Wezel RJ (2013) Synchrony in Parkinson's disease: importance of intrinsic properties of the external globus pallidus. Front Syst Neurosci 7:60. CrossRef Medline

Sherman SM, Guillery RW (2011) Distinct functions for direct and transthalamic corticocortical connections. J Neurophysiol 106:1068-1077. CrossRef Medline

Shipp S, Adams RA, Friston KJ (2013) Reflections on agranular architecture: predictive coding in the motor cortex. Trends Neurosci 36:706-716. CrossRef Medline

Silberstein P, Pogosyan A, Kühn AA, Hotton G, Tisch S, Kupsch A, DowseyLimousin P, Hariz MI, Brown P (2005) Cortico-cortical coupling in Parkinson's disease and its modulation by therapy. Brain 128:1277-1291. CrossRef Medline

Stam CJ, Nolte G, Daffertshofer A (2007) Phase lag index: assessment of functional connectivity from multi channel EEG and MEG with diminished bias from common sources. Hum Brain Mapp 28:1178-1193. CrossRef Medline

Stein E, Bar-Gad I (2013) $\beta$ oscillations in the cortico-basal ganglia loop during parkinsonism. Exp Neurol 245:52-59. CrossRef Medline

Stoffers D, Bosboom JL, Deijen JB, Wolters EC, Stam CJ, Berendse HW (2008) Increased cortico-cortical functional connectivity in early-stage Parkinson's disease: an MEG study. Neuroimage 41:212-222. CrossRef Medline

Villalba RM, Smith Y (2013) Differential striatal spine pathology in Parkinson's disease and cocaine addiction: a key role of dopamine? Neuroscience 251:2-20. CrossRef Medline

Vinck M, Oostenveld R, van Wingerden M, Battaglia F, Pennartz CM (2011) An improved index of phase synchronization for electrophysiological data in the presence of volume-conduction, noise and sample-size bias. Neuroimage 55:1548-1565. CrossRef Medline

Vinck M, Huurdeman L, Bosman CA, Fries P, Battaglia FP, Pennartz CM, Tiesinga PH (2015) How to detect the Granger-causal flow direction in the presence of additive noise? Neuroimage 108:301-318. CrossRef Medline

Wu T, Hallett M, Chan P (2015a) Motor automaticity in Parkinson's disease. Neurobiol Dis 82:226-234. CrossRef Medline

Wu T, Hou Y, Hallett M, Zhang J, Chan P (2015b) Lateralization of brain activity pattern during unilateral movement in Parkinson's disease. Hum Brain Mapp 36:1878-1891. CrossRef Medline

Žarić G, Correia JM, Fraga González G, Tijms J, van der Molen MW, Blomert L, Bonte M (2017) Altered patterns of directed connectivity within the reading network of dyslexic children and their relation to reading dysfluency. Dev Cogn Neurosci 23:1-13. CrossRef Medline 